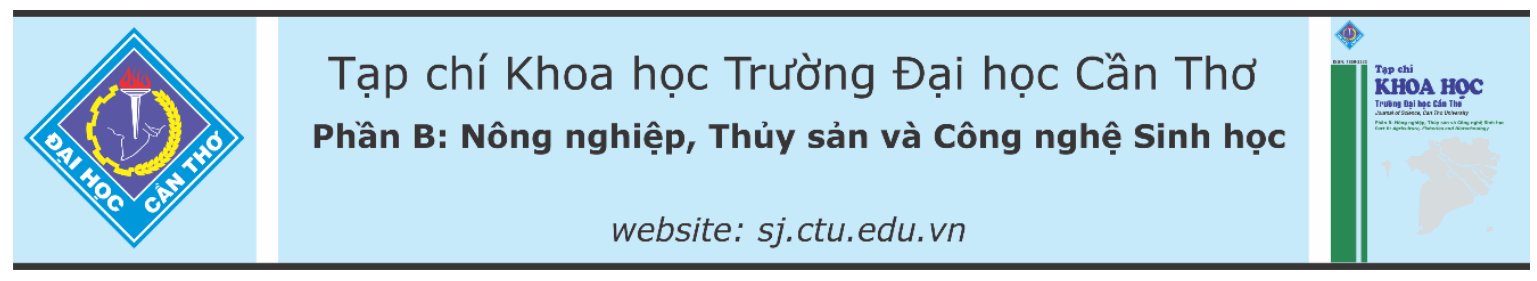

DOI:10.22144/ctu.jvn.2021.045

\title{
ẢNH HƯởNG CỦA NỒNG ĐỌ NAPHTHALENE ACETIC ACID ĐẾN SINH TRƯỞNG, NĂNG SUẤT VÀ HẤP THU N, P, K CỦA MÈ ĐEN (Sesamum indicum L.) TRÊN ĐẤT PHÙ SA KHÔNG ĐƯợC BỒI TẠI QUẬN Ô MÔN, THÀNH PHỐ CẦN THƠ
}

\author{
Nguyễn Quốc Khương ${ }^{1}$, Nguyễn Đoàn Quốc Duy ${ }^{2}$, Trần Ngọc Hữu ${ }^{1}$ và Lê Vĩnh Thúc ${ }^{1 *}$ \\ ${ }^{1}$ Bộ môn Khoa học cây trồng, Khoa Nông nghiệp, Truờng Đại học Cần Tho \\ ${ }^{2}$ Hoc viên cao học ngành Khoa học cây trồng Khóa 25, Trường Đại học Cần Tho \\ *Người chịu trách nhiệm về bài viết: Lê Vĩnh Thúc (email: lvthuc@ctu.edu.vn)
}

\section{Thông tin chung:}

Ngày nhận bài: 15/10/2020

Ngày nhận bài sưa: 11/12/2020

Ngày duyệt đăng: 28/04/2021

\section{Title:}

Effects of spraying naphthalene acetic acid on growth and yield of black sesame (Sesamum indicum L.) in alluvial soil in dyke in $O$ Mon district, Can Tho city

\section{Tù khóa:}

Đất phù sa không được bồi, mè đen, naphthalene acetic acid, Sesamum indicum $L$.

\section{Keywords:}

Alluvial soil in dyke, black sesame, naphthalene acetic acid, Sesamum indicum $L$.

\begin{abstract}
The objective of this study was to determine the proper concentration of spraying naphthalene acetic acid (NAA) to obtain the highest growth and yield of black sesame (Sesamum indicum L.). A field experiment was conducted in a randomized complete block design with six treatments and five replications in $O$ Mon district, Can Tho city. Treatments included (i) control (no spraying NAA, spraying tap water), (ii) spraying NAA at concentration of $25 \mathrm{ppm}$, (iii) spraying NAA at concentration of $50 \mathrm{ppm}$, (iv) spraying NAA at concentration of $75 \mathrm{ppm}$, ( $v$ ) spraying NAA at concentration of 100 ppm and (vi) spraying NAA at concentration of 150 ppm. The results showed that spraying NAA at concentration of $50 \mathrm{ppm}$ contributed to increase the number of leaves per plant, content of chlorophyll a, content of chlorophyll total, percentage of fulfil capsule, concentration of $N, P$ in leaves, number of capsules per plant, dry biomass and grain yield of black sesame.
\end{abstract}

\section{TÓM TẮT}

Nghiên cưu được thực hiện nhằm tìm ra nồng độ naphthalene acetic acid (NAA) phù hợp cho sinh trưởng và năng suất mè cao nhất. Thí nghiệm đurợc bố trí khối hoàn toàn ngẫu nhiên với sáu nghiệm thức, năm lạ̣p lại, mỗi lặp lại $25 \mathrm{~m}^{2}$ tại quận Ô Môn, thành phố Cần Tho: Các nghiệm thức thi nghiệm bao gồm (i) không phun NAA (đối chứng, phun nước), (ii) phun $N A A$ với nồng độ $25 \mathrm{ppm}$, (iii) phun NAA với nồng độ 50 ppm, (iv) phun $N A A$ với nồng độ 75 ppm, (v) phun NAA với nồng độ 100 ppm và (vi) phun NAA với nồng độ 150 ppm. Kết quả cho thấy phun bổ sung naphthalene acetic acid với nồng độ 50 ppm đã góp phần tăng số lá/cây, chlorophyll a, chlorophyll tổng, tỉ lệ đậu trái mè, hàm luợng dinh dương $N, P$ trong lá, số trái/cây, sinh khối khô và năng suất hạt mè.

\section{GIỚI THIỆU}

Trong những năm gần đây, chi phí sản xuất lúa vụ Hè Thu của mô hình ba vụ lúa thường cao, nhưng mang lại hiệu quả kinh tế thấp hơn so với mô hình lúa-mè-lúa (Trần Thị Hồng Thắm và ctv., 2016). Vì thế, tại nhiều địa phương ở Đồng bằng sông Cửu Long, nông dân đã chuyển sang canh tác mè thay cho vụ lúa Xuân Hè, trong đó có thành phố Cần Thơ, với diện tích mè năm 2015 là 2.630 ha được trồng nhiều nhất tại quận Ô Môn (Niên giám thống kê, 2016). Tuy nhiên, diện tích mè tại Ô Môn đang giảm dần do gặp khó khăn trong tiêu thụ và kỹ thuật xử lý đậu trái vào giai đoạn trổ hoa vì hoa mè thường rụng ở điều kiện thời tiết bất lợi như mưa từ đó làm giảm năng suất. Nhiều nghiên cứu chỉ ra rằng bổ sung chất 
điều hòa sinh trưởng thực vật trong giai đoạn ra hoa tăng khả năng đậu trái cho cây (Võ Quang Sáng, 2006). Trong đó, chất điều hòa sinh trưởng naphthalene acetic acid là một loại auxin tổng hợp, thường được sử dụng để kích thích đậu trái (Võ Quang Sáng, 2006), NAA có nhiều tác dụng khác nhau trong việc kiểm soát sự ra hoa, phòng ngừa rụng quả và tăng hình thành quả ở các cây khác nhau (Prakash et al., 2001; Siddik, 2016). Vì vậy, nghiên cứu được thực hiện nhằm tìm ra nồng độ naphthalene acetic acid (NAA) phù hợp để đạt được sinh trưởng và năng suất mè cao nhất.

\section{VẬT LIỆU VÀ PHƯƠNG PHÁP}

\subsection{Thời gian và địa điểm}

Thí nghiệm được thực hiện từ tháng 2 đến tháng 5 năm 2019 tại khu vực Thới Thuận, phường Phước Thới, quận Ô Môn, thành phố Cần Thơ.

\subsection{Vật liệu}

Giống mè: Giống mè đen 2 vỏ Thốt Nốt được sử dụng trong nghiên cứu này.

Phân bón: Phân vô cơ gồm urê $(46 \% \mathrm{~N})$, DAP $\left(18 \% \mathrm{~N}, 46 \% \mathrm{P}_{2} \mathrm{O}_{5}\right)$, clorua kali $\left(60 \% \mathrm{~K}_{2} \mathrm{O}\right)$. Chất điều hòa sinh trưởng được sử dụng là naphthalene acetic acid.

Đặc tính đất vùng nghiên cứu được thể hiện ở Bảng 1.

Bảng 1. Đặc tính đất đầu vụ của ruộng thí nghiệm

\begin{tabular}{|c|c|c|c|}
\hline Chỉ tiêu & Đơn vị & $\begin{array}{r}\text { Giá trị } \\
\text { tầng } \\
0-20 \mathrm{~cm}\end{array}$ & $\begin{array}{r}\text { Giá trị } \\
\text { tầng } \\
20-40 \mathrm{~cm} \\
\end{array}$ \\
\hline $\mathrm{pH}_{\mathrm{KCl}}$ & - & 3,90 & 4,27 \\
\hline $\mathrm{pH}_{\mathrm{H} 2 \mathrm{O}}$ & - & 4,81 & 5,35 \\
\hline $\mathrm{EC}$ & $\mathrm{mS} \mathrm{cm}-1$ & 0,32 & 0,18 \\
\hline CEC & meq $100 \mathrm{~g}^{-1}$ & 17,8 & 16,5 \\
\hline Cacbon & $\%$ & 2,44 & 0,93 \\
\hline $\mathrm{N}_{\text {Tổng số }}$ & $\%$ & 0,18 & 0,14 \\
\hline $\mathrm{NH}_{4}^{+}$ & $\mathrm{mg} \mathrm{kg}^{-1}$ & 29,5 & 31,0 \\
\hline PTổng số & $\%$ & 0,028 & 0,024 \\
\hline $\mathrm{P}_{\mathrm{Dễ} \mathrm{tiêu}}$ & $\mathrm{mg} \mathrm{kg}^{-1}$ & 51,2 & 35,7 \\
\hline P-Al & $\mathrm{mg} \mathrm{kg}^{-1}$ & 43,3 & 17,4 \\
\hline $\mathrm{P}-\mathrm{Fe}$ & $\mathrm{mg} \mathrm{kg}^{-1}$ & 7,30 & 6,50 \\
\hline $\mathrm{P}-\mathrm{Ca}$ & $\mathrm{mg} \mathrm{kg}^{-1}$ & 1,70 & 23,3 \\
\hline $\mathrm{Al}^{3+}$ & meq $\mathrm{Al}^{3+} 100 \mathrm{~g}^{-1}$ & 0,37 & 0,32 \\
\hline $\mathrm{Fe}_{\text {Hòa tàn }}$ & $\mathrm{mg} \mathrm{kg}^{-1}$ & 1,52 & 1,33 \\
\hline $\mathrm{Fe}^{2+}$ & $\mathrm{mg} \mathrm{kg}^{-1}$ & 2,94 & 3,43 \\
\hline Acid $_{\text {Tổng }}$ & meq $100 \mathrm{~g}^{-1}$ & 0,675 & 1,375 \\
\hline $\mathrm{Fe}_{2} \mathrm{O}_{3}$ & $\%$ & 0,321 & 0,178 \\
\hline $\mathrm{Na}^{+}$ & meq $\mathrm{Na}^{+} 100 \mathrm{~g}^{-1}$ & 0,32 & 0,37 \\
\hline $\mathrm{K}^{+}$ & meq $\mathrm{K}^{+} 100 \mathrm{~g}^{-1}$ & 0,10 & 0,11 \\
\hline $\mathrm{Mg}^{2+}$ & meq $\mathrm{Mg}^{2+} 100 \mathrm{~g}^{-1}$ & 3,07 & 3,07 \\
\hline $\mathrm{Ca}^{2+}$ & meq $\mathrm{Ca}^{2+} 100 \mathrm{~g}^{-1}$ & 1,32 & 1,47 \\
\hline
\end{tabular}

\subsection{Phương pháp}

Thí nghiệm được bố trí theo thể thức khối hoàn toàn ngẫu nhiên với sáu nghiệm thức, năm lặp lại, mỗi lần lặp lại $25 \mathrm{~m}^{2}$. Các nghiệm thức thí nghiệm gồm (i) không phun NAA (đối chứng, phun nước), (ii) phun NAA với nồng độ 25 ppm, (iii) phun NAA với nồng độ 50 ppm, (iv) phun NAA với nồng độ 75 ppm, (v) phun NAA với nồng độ 100 ppm, (vi) phun NAA với nồng độ 150 ppm.

Bón phân cho mè theo công thức: $90 \mathrm{~N}-60 \mathrm{P}_{2} \mathrm{O}_{5-}$ $30 \mathrm{~K}_{2} \mathrm{O}$. Lần 1 : bón $1 / 3$ đạm và toàn bộ lân và kali một ngày trước khi gieo. Lần 2 : bón $1 / 3$ đạm vào thời điểm 32 ngày sau gieo (NSG). Lần 3 : bón $1 / 3$ đạm vào thời điểm $46 \mathrm{NSG}$. Chất điều hòa sinh trưởng naphthalene acetic acid được pha loãng với các nồng độ: 25 ppm; 50 ppm; 75 ppm; 100 ppm; $150 \mathrm{ppm}$ và phun vào thời điểm 25 và $35 \mathrm{NSG}$.

\section{Các chỉ tiêu theo dõi}

Chiều cao cây $(\mathrm{cm})$ : đo từ mặt đất đến đỉnh sinh trưởng cao nhất của cây vào thời điểm 56 NSG. Số lá trên thân chính (lá): đếm số lá trên cây từ lá thật đầu tiên đến lá ngọn có cuống lá $1 \mathrm{~cm}$ vào thời điểm 56 NSG. Đo chiều cao và đếm số lá trên 20 cây của mỗi lô thí nghiệm. Đo Chlorophyll a, b ( $\mu \mathrm{g} / \mathrm{g}$ lá tươi) trên lá theo phương pháp của Moran (1982) tại thời điểm 44 và $65 \mathrm{NSG}$, đo 2 lá mỗi lô ở lá thứ 12 từ mặt đất. Đo độ đóng mở khí khổng: dùng máy SC-1 Leaf Porometer đo độ đóng mở khí khổng thời điểm 35 và 63 NSG. Đo lá thứ 12 từ mặt đất trở lên, vào thời điểm 9 giờ, đo 4 lá trên mỗi lô (Nghĩa là 20 lá cho 1 lặp lại). Số hoa trên thân chính (hoa): đếm số hoa trên cây từ khi hoa nở đầu tiên đến hoa cuối cùng. Số trái trên cây (trái): đếm tổng số trái trên cây. Số hạt trên trái (hạt): đếm tổng số hạt của 04 trái/cây ở giữa đoạn thân mang trái. Khối lượng hạt trên cây (g): cân khối lượng hạt của 4 cây, sau đó tính giá trị trung bình cho 1 cây. Khối lượng 1.000 hạt $(\mathrm{g})$ : Đếm ngẫu nhiên 1.000 hạt ở mỗi nghiệm thức rồi sau đó dùng cân điện tử 3 số lẻ để cân. Sinh khối khô thân, lá (tấn ha ${ }^{-1}$ ): cân sinh khối khô của cây lúc thu hoạch trong diện tích $5 \mathrm{~m}^{2}$ rồi quy ra sinh khối tấn $\mathrm{ha}^{-1}$. Năng suất (tấn ha $\mathrm{a}^{-1}$ ): cân khối lượng hạt mè trong $5 \mathrm{~m}^{2}$ và quy ra năng suất tấn $\mathrm{ha}^{-1}$ ơ ẩm độ $8 \%$. Phân tích hàm lượng $\mathrm{N}, \mathrm{P}, \mathrm{K}$ trên lá thời điểm 44 NSG theo phương pháp của Houba et al. (1997).

\subsection{Xử lý số liệu}

Số liệu được nhập và xử lý bằng phần mềm Microsoft Excel. Sử dụng phần mềm SPSS 16.0 phân tích phương sai, so sánh khác biệt trung bình giữa các nghiệm thức bằng kiểm định Ducan. 


\section{KẾT QUẢ VÀ THẢO LUẬN}

\section{1. Ảnh hưởng của phun NAA đến chiều cao cây mè và số lá mè trồng tại Ô Môn}

Chiều cao cây mè của các nghiệm thức phun NAA khác nhau chưa khác biệt ý nghĩa thống kê. Trong đó, chiều cao cây mè được ghi nhận từ 105,3 đến $114,2 \mathrm{~cm}$. Ngoài ra, phun bổ sung NAA đã giúp

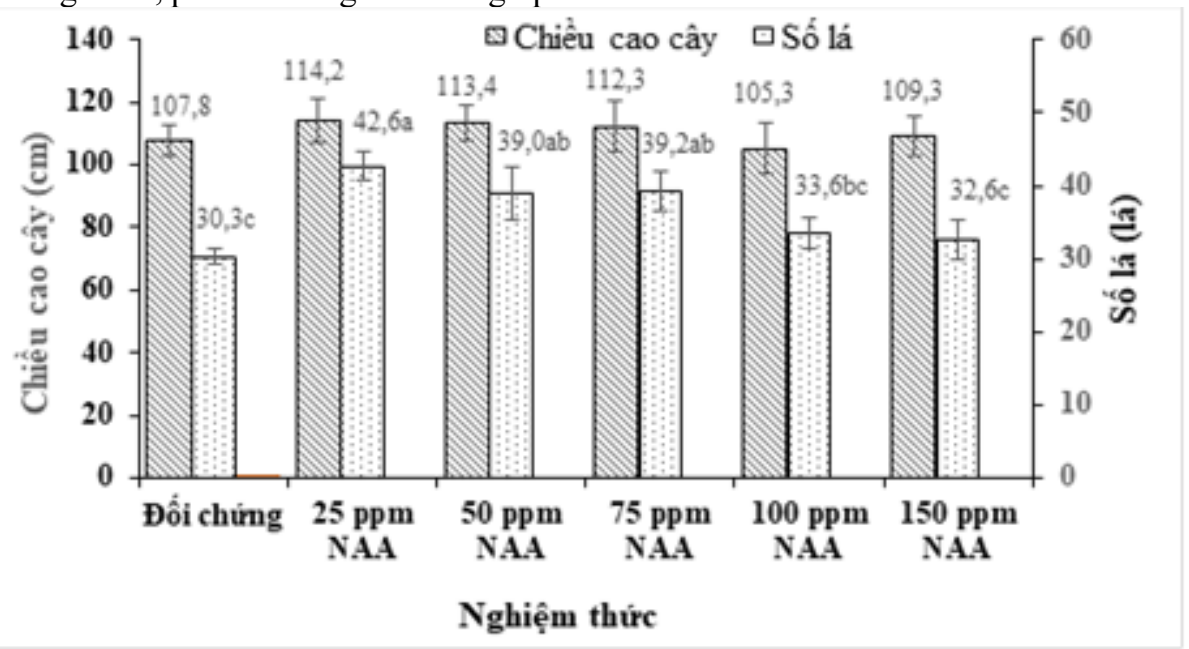

Hình 1. Ảnh hưởng của phun NAA đến chiều cao cây mè và số lá mè trồng tại Ô Môn vào thời điểm thu hoạch

3.2. Ảnh hưởng của phun NAA đến diễn biến số hoa trên cây mè và tỉ lệ đậu trái mè trồng tại Ô Môn

Số hoa của các nghiệm thức được ghi nhận từ thời điểm 36 đến 66 NSG. Số hoa mè tăng khác biệt có ý nghĩa thống kê $1 \%$ đối với nghiệm thức phun NAA từ 25 đến 75 ppm (36,0-36,9 hoa trên cây) so với không bổ sung NAA (33,7 hoa trên cây). Tuy nhiên, phun NAA ở khoảng nồng độ 100-150ppm ghi nhận số hoa trên cây không đồi so với nghiệm thức đối chứng vào thời điểm $66 \mathrm{NSG}$ (Bảng 2). Do cải thiện về số lá mè. Các nghiệm thức phun NAA từ 25 đến $75 \mathrm{ppm}$ đã giúp tăng số là mè so với nghiệm thức không bổ sung NAA, với số lá 39,042,6 và 30,3 lá, theo cùng thứ tự. Tuy nhiên, phun NAA ở khoảng nồng độ 100-150 ppm chưa cải thiện về số lá so với đối chứng không bổ sung NAA vào thời điểm 56 NSG (Hình 1).

Bảng 2. Ảnh hưởng của phun NAA đến diê̂n biến số hoa trên cây mè và tỉ lệ đậu trái mè trồng tại Ô Môn

\begin{tabular}{|c|c|c|c|c|c|}
\hline \multirow{3}{*}{$\begin{array}{c}\text { Nồng độ NAA } \\
\text { (ppm) }\end{array}$} & \multicolumn{4}{|c|}{ Số hoa trên cây (Hoa) } & Tỉ lệ đậu trái (\%) \\
\hline & & & NSG & & \\
\hline & 36 & 46 & 56 & 66 & 66 \\
\hline 0 & 6,8 & $20,6^{\mathrm{c}}$ & $30,3^{\mathrm{b}}$ & $33,7^{\mathrm{c}}$ & $60,7^{b}$ \\
\hline 25 & 7,1 & $24,7^{\mathrm{a}}$ & $34,0^{\mathrm{a}}$ & $36,9^{\mathrm{a}}$ & $71,3^{\mathrm{a}}$ \\
\hline 50 & 8,7 & $22,4^{\mathrm{abc}}$ & $32,9^{\mathrm{ab}}$ & $36,0^{\mathrm{ab}}$ & $71,7^{\mathrm{a}}$ \\
\hline 75 & 8,0 & $23,2^{\mathrm{ab}}$ & $33,8^{\mathrm{ab}}$ & $36,5^{\mathrm{a}}$ & $68,5^{\mathrm{a}}$ \\
\hline 100 & 7,2 & $22,0^{\mathrm{bc}}$ & $33,0^{\mathrm{a}}$ & $34,6^{\mathrm{bc}}$ & $67,4^{\mathrm{a}}$ \\
\hline 150 & 7,2 & $20,4^{c}$ & $26,6^{\mathrm{c}}$ & $32,8^{\mathrm{c}}$ & $70,5^{a}$ \\
\hline $\mathrm{F}$ & $\mathrm{ns}$ & $* *$ & $* *$ & $* *$ & ** \\
\hline $\mathrm{CV}(\%)$ & 16,7 & 7,6 & 6,7 & 3,8 & 7,2 \\
\hline
\end{tabular}

Ghi chú: Trong cùng một cột số có chũ theo sau giống nhau khác biệt không có ý nghĩa thống kê, ns; khác biệt ý nghĩa thống kê 1\% (**). NSG: ngày sau gieo 


\section{3. Ảnh hưởng của phun NAA đến hàm lượng chlorophyll trong lá mè trồng tại Ô Môn}

Hàm lượng chlorophyll trong lá của các nghiệm thức được ghi nhận vào thời điểm 44 đến 65 NSG. Nhìn chung, chỉ có sự khác biệt ý nghĩa thống kê 5\% giữa các nghiệm thức về hàm lượng chlorophyll a và chlorophyll tổng. Vào thời điểm $65 \mathrm{NSG}$, chỉ có nghiệm thức phun NAA ở nồng độ 50 và 100 ppm có hàm lượng chlorophyll a cao hơn so với đối Bảng 3. Hàm lượng chlorophyll trong lá trồng tại Ô Môn vào thời điểm 44 và 65 ngày sau gieo

\begin{tabular}{|c|c|c|c|c|c|c|}
\hline \multirow{3}{*}{ Nồng độ NAA (ppm) } & \multicolumn{3}{|c|}{44 NSG } & \multicolumn{3}{|c|}{65 NSG } \\
\hline & \multicolumn{6}{|c|}{ Chlorophyll ( $\mu \mathrm{g} / \mathrm{g}$ lá tươi) } \\
\hline & $\mathbf{a}$ & b & Tổng & $\mathbf{a}$ & b & Tổng \\
\hline 0 & $9,1^{\mathrm{c}}$ & 1,8 & $16,6^{\mathrm{c}}$ & $9,5^{\mathrm{b}}$ & 2,5 & $17,8^{\mathrm{c}}$ \\
\hline 25 & $10,4^{b}$ & 2,0 & $19,1^{\mathrm{ab}}$ & $10,8^{\mathrm{ab}}$ & 2,3 & $19,9^{\mathrm{bc}}$ \\
\hline 50 & $11,3^{\mathrm{a}}$ & 2,0 & $20,6^{\mathrm{a}}$ & $12,2^{\mathrm{a}}$ & 3,6 & $23,2^{\mathrm{a}}$ \\
\hline 75 & $10,4^{b}$ & 2,1 & $19,1^{\mathrm{ab}}$ & $11,0^{\mathrm{ab}}$ & 2,8 & $20,6^{\mathrm{abc}}$ \\
\hline 100 & $10,0^{\mathrm{b}}$ & 2,1 & $18,5^{\mathrm{b}}$ & $11,4^{\mathrm{a}}$ & 2,9 & $21,3^{\mathrm{ab}}$ \\
\hline 150 & $9,8^{\mathrm{bc}}$ & 2,2 & $18,1^{\mathrm{bc}}$ & $11,0^{\mathrm{ab}}$ & 2,7 & $20,5^{\mathrm{abc}}$ \\
\hline $\mathrm{F}$ & $* *$ & ns & $* *$ & $*$ & $\mathrm{~ns}$ & $*$ \\
\hline $\mathrm{CV}(\%)$ & 6,4 & 23,1 & 6,3 & 10,9 & 29,6 & 10,4 \\
\hline
\end{tabular}

Ghi chú: Trong cùng một cột số có chũ theo sau giống nhau khác biệt không có ý nghĩa thống kê, ns; khác biệt ý nghĩa thống kê 1\%(**). NSG: ngày sau gieo

\section{4. Ảnh hưởng của phun NAA đến hàm lượng dưỡng chất $\mathrm{N}, \mathrm{P}, \mathrm{K}$ trong lá mè trồng tại Ô Môn}

Phun bổ sung NAA ở các nồng độ khác nhau đã tăng hàm lượng dinh dưỡng NPK trong lá mè. Đối với dưỡng chất $\mathrm{P}, \mathrm{N}, \mathrm{K}$, phun NAA ở các nồng độ tương ứng là 25,50 và 75 ppm trở lên đã tăng hàm lượng trong lá. Cụ thể là, phun NAA từ 25 đến 150 ppm đạt hàm lượng lân trong lá $0,72-0,75 \%$ trong khi nghiệm thức không phun NAA chỉ đạt hàm lượng lân $0,60 \%$. Tương tự, đối với dưỡng chất đạm là $2,77-2,84 \%$ so với $2,14 \%$; dưỡng chất kali là 3,50 $3,67 \%$ so với $1,48 \%$ (Bảng 4 ).

Bảng 4. Hàm lượng dưỡng chất $\mathrm{N}, \mathrm{P}, \mathrm{K}$ trong lá vào thời 52 ngày sau gieo

\begin{tabular}{crrr}
\hline Nồng độ & \multicolumn{1}{c}{$\mathbf{N}$} & $\mathbf{P}$ & $\mathbf{K}$ \\
\cline { 2 - 4 } NAA (ppm) & & $(\mathbf{\%} \mathbf{D W})$ & \\
\hline 0 & $2,14^{\mathrm{b}}$ & $0,60^{\mathrm{b}}$ & $1,48^{\mathrm{b}}$ \\
25 & $2,56^{\mathrm{ab}}$ & $0,72^{\mathrm{a}}$ & $1,57^{\mathrm{b}}$ \\
50 & $2,84^{\mathrm{a}}$ & $0,75^{\mathrm{a}}$ & $1,61^{\mathrm{b}}$ \\
75 & $2,84^{\mathrm{a}}$ & $0,73^{\mathrm{a}}$ & $3,50^{\mathrm{a}}$ \\
100 & $2,80^{\mathrm{a}}$ & $0,75^{\mathrm{a}}$ & $3,67^{\mathrm{a}}$ \\
150 & $2,77^{\mathrm{a}}$ & $0,73^{\mathrm{a}}$ & $3,53^{\mathrm{a}}$ \\
\hline $\mathrm{F}$ & $*$ & $*$ & $* *$ \\
$\mathrm{CV}(\%)$ & 14,1 & 10,6 & 9,6 \\
\hline
\end{tabular}

Ghi chú: Trong cùng một cột số có chũ theo sau giống nhau khác biệt không có ý nghĩa thống kê, ns; khác biệt ý nghĩa thống kê 1\% (**). DW: trọng luợng khô chứng, với giá trị 11,4-12,2 $\mu \mathrm{g} / \mathrm{g}$ so với $9,5 \mu \mathrm{g} / \mathrm{g}$, theo cùng thứ tự. Bên cạnh đó, hàm lượng chlorophyll $\mathrm{b}$ được xác định 2,3-3,6 $\mu \mathrm{g} / \mathrm{g}$. Đối với hàm lượng chlorophyll tổng, chỉ có nghiệm thức phun NAA ở nồng độ 50 và 100 ppm cao khác biệt ý nghĩa thống kê 5\% so với không bổ sung, có giá trị lần lượt là 23,2 và $21,3 \mu \mathrm{g} / \mathrm{g}$ (Bảng 3 ). Theo Liang et al. (2011), hàm lượng chlorophyll tăng khi được phun bổ sung NAA, và kết quả trong thí nghiệm này cũng đạt tương tự. 
Bảng 5. Ảnh hưởng của phun NAA đến thành phần năng suất mè trồng tại Ô Môn

\begin{tabular}{crrrrrr}
\hline $\begin{array}{c}\text { Nồng độ NAA } \\
(\mathbf{p p m})\end{array}$ & Số trái/cây & Chiều dài trái & Chiều rộng trái & Số hạt/trái & KL hạt/cây & KL 1000 hạt \\
\cline { 2 - 7 } & $($ trái) & $(\mathbf{m m})$ & $(\mathbf{m m})$ & $(\mathbf{h a ̣ t )}$ & $(\mathbf{g})$ & $(\mathbf{g})$ \\
\hline 0 & $20,4^{\mathrm{b}}$ & $24,7^{\mathrm{b}}$ & 11,5 & 99,5 & $6,53^{\mathrm{b}}$ & 2,84 \\
25 & $25,6^{\mathrm{a}}$ & $26,8^{\mathrm{a}}$ & 11,7 & 111,8 & $7,66^{\mathrm{a}}$ & 3,19 \\
50 & $25,3^{\mathrm{a}}$ & $25,9^{\mathrm{ab}}$ & 11,7 & 117,1 & $7,62^{\mathrm{a}}$ & 3,21 \\
75 & $24,8^{\mathrm{a}}$ & $26,2^{\mathrm{a}}$ & 11,9 & 115,0 & $7,39^{\mathrm{ab}}$ & 3,17 \\
100 & $22,9^{\mathrm{ab}}$ & $24,9^{\mathrm{b}}$ & 11,6 & 104,7 & $6,76^{\mathrm{ab}}$ & 3,07 \\
150 & $22,9^{\mathrm{ab}}$ & $24,8^{\mathrm{b}}$ & 11,6 & 105,2 & $6,63^{\mathrm{b}}$ & 3,01 \\
\hline $\mathrm{F}$ & $*$ & $* *$ & $\mathrm{~ns}$ & $\mathrm{~ns}$ & $*^{2}$ & $\mathrm{~ns}$ \\
$\mathrm{CV}(\%)$ & 9,2 & 3,9 & 3,0 & 11,2 & 9,4 & 13,8 \\
\hline
\end{tabular}

Ghi chú: Trong cùng một cột số có chũ theo sau giống nhau khác biệt không có ý nghĩa thống kê, ns; khác biệt ý nghĩa thống kê 1\%(**). KL: khối lượng

\section{6. Ảnh hưởng của phun NAA đến sinh khối thân, lá khô và năng suất hạt mè trồng tại Ô Môn}

Phun bổ sung NAA ở nồng độ 50 hay 75 ppm đã góp phần tăng sinh khối khô của thân, lá mè $(3,29-$

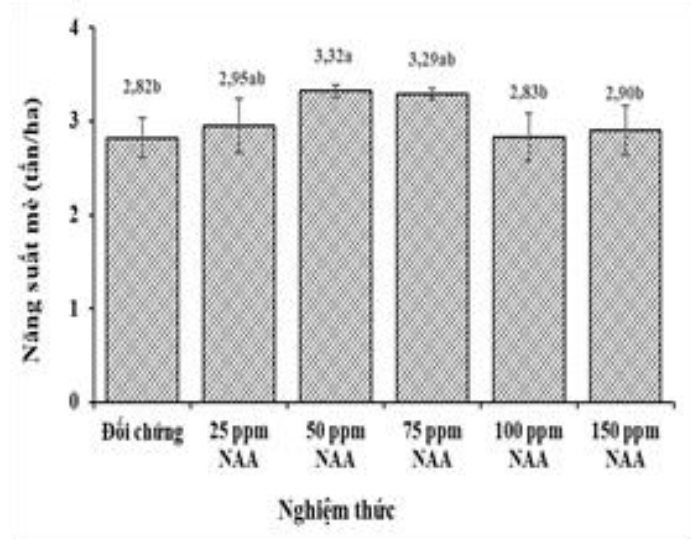

(a)
3,32 tấn ha ${ }^{-1}$ ) so với nghiệm thức đối chứng 2,82 tấn $\mathrm{ha}^{-1}$. Tuy nhiên, phun bổ sung NAA ở nồng độ 25 , 100 hay 150 ppm ghi nhận khác biệt không có ý nghĩa thống kê về sinh khối thân, lá khô so với đối chứng (Hình 2a).

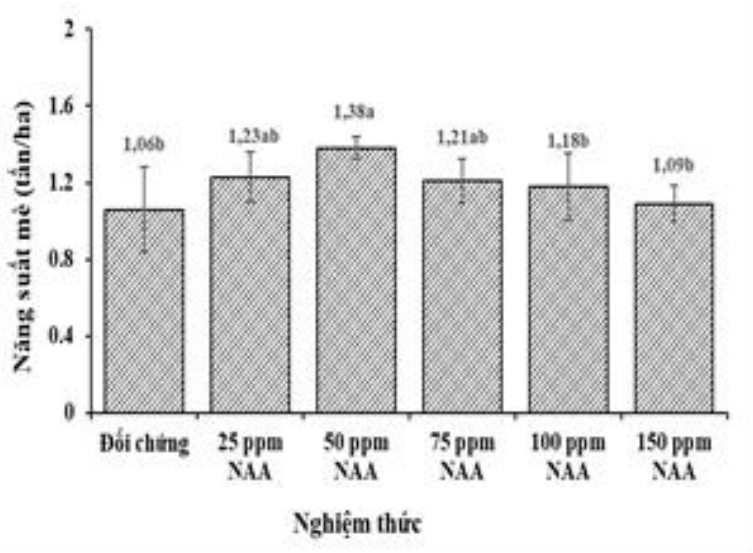

(b)

Hình 2. Ảnh hưởng của phun NAA đến (a) sinh khối thân, lá khô và (b) năng suất hạt mè trồng tại Ô Môn Ghi chú: số có chĩ theo sau khác nhau khác biệt có ý nghĩa thống kê 1\% (**)

Năng suất hạt mè giữa các nghiệm thức khác biệt có ý nghĩa thống kê 5\%. Trong đó, nghiệm thức phun bổ sung NAA ở nồng độ 50 ppm đạt năng suất cao nhất 1,38 tấn $h^{-1}$ trong khi nghiệm thức không phun NAA chỉ có năng suất 1,06 tấn ha ${ }^{-1}$. Các nồng độ NAA thấp hơn (25 ppm) hoặc cao hơn (75-150 ppm) chưa dẫn đến sự khác biệt năng suất có ý nghĩa thống kê so với không phun NAA (Hình 2b). Phun bổ sung NAA đã làm gia tăng năng suất lúa ở Bangladesh so với đối chứng (Adam \& Jahan, 2011). Kết quả nghiên cứu trên lúa mì cũng cho thấy sử dụng NAA với nồng độ $25 \mathrm{mg} / \mathrm{l}$ vào thời điểm 20,35 và 50 ngày sau gieo cho tổng sinh khối khô của lúa mì cao hơn so với phun NAA vào thời điểm 35 và 50 ngày sau gieo (Jahan et al., 2019).

\section{KẾT LUẬN}

Phun naphthalene acetic acid với nồng độ 50 ppm giúp tăng số lá/cây, chlorophyll a, chlorophyll tổng, tỉ lệ đậu trái, hàm lượng dinh dưỡng $\mathrm{N}, \mathrm{P}$ trong lá, số trái/cây sinh khối khô và năng suất hạt mè.

\section{LỜI CẢM TẠ}

Đề tài này được tài trợ bởi Dự án Nâng cấp Trường Đại học Cần Thơ VN14-P6 bằng nguồn vốn vay ODA từ Chính phủ Nhật Bản.

\section{TÀI LIÊU THAM KHẢO}

Adam, A. G., \& Jahan, N. (2011). Effects of naphthalene acetic acid on yield attributes and 
yield of two varieties of rice (Oryza sativa L.). Bangladesh Journal of Botany, 40(1), 97-100.

Houba, V. J. G., Novozamsky, I., Temminghof, E. J. M. (1997). Soil and Plant Analysis, Part 5. Department of Soil Science and Plant Nutrition. Wageningen Agricultural University. The Netherlands.

Jahan, M. A. H. S., Hossain, A., Jaime, A., Da Silva, T., El Sabagh, A., Rashid, M. H., \& Barutçular, C. (2019). Effect of naphthaleneacetic acid on root and plant growth and yield of ten irrigated wheat genotypes. Pakistan Journal of Botany, 51(2), 451-459.

Liang, P., Xing, X. H., Zhou, Q., Han, L. L., Tian, Y. D., Zhang, G. Z., ... \& Jiang, H. D. (2011). Effect of NAA on growth and photosynthetic characteristic of soybean seedling under drought and re-watering. Soybean Science, 30(1), 50-55.

Moran, R. (1982). Formulae for determination of chlorophyllous pigments extracted with $\mathrm{N}, \mathrm{N}-$ dimethylformamide. Plant Physiology, 69(6), 1376-1381.

Niên giám thống kê, 2016. Niên giám thống kê thành phố Cần Thơ năm 2017. Nhà xuất bản thống kê. Cục Thống kê thành phố Cần Thơ.
Prakash, P. (2001). Indian Medicinal plants, Forgotten Healers, A guide to ayurvedic herbal medicine pp. 229-230.

Rajesh, K., Narender Reddy, S., Pratap Kumar Reddy, A., \& Gopal Singh, B. (2014). Effect of plant growth regulating compounds on chlorophyll, photosynthetic rate and yield of green gram. International Journal of Development Research, 4, 1110-1112.

Siddik, A., Shirazy, B. J., Islam, M. M., Hoque, A., $\&$ Haque, M. (2016). Combined effect of nitrogen and NAA on the yield of Sesame (Sesamum indicum L.). Scientia, 13(1), 1-9.

Singh, M., John, S. A., Rout, S., \& Patra, S. S. (2015). Effect of GA3 and NAA on growth and quality of garden pea (Pisum sativum L.) cv. Arkel. Bioscan, 10(3), 381-383.

Trần Thị Hồng Thắm, 2016. Nghiên cứu phát triển cây vừng trong hệ thống canh tác có lúa vùng đất xám Đồng Tháp Mười. Hội thảo Quốc gia về Khoa học Cây trồng lần thứ hai, ngày 1112/8/2016, Cần Thơ. Nhà xuất bản Viện Khoa học Nông nghiệp Việt Nam. Hà Nội, 722-728.

Võ Quang Sáng, Hồ Minh Tấn và Nguyễn Quang Thạch (2006). Giáo trình sinh lý thực vật. Nhà xuất bản Nông nghiệp, Hà Nội. 